\title{
"An Odyssey of Third Space Endoscopy"-from Entry into the Tunnel to Entry into the Peritoneal Cavity
}

\author{
Harshal S. Mandavdhare ${ }^{1}$ Shubhra Mishra ${ }^{1}$ Jayanta Samanta ${ }^{1} \quad$ Jimil Shah ${ }^{1}$ Rakesh Kochhar ${ }^{1}$ \\ ${ }^{1}$ Department of Gastroenterology, Postgraduate Institute of \\ Address for correspondence Harshal S. Madhavdhare, MD, DM \\ (Gastroenterol), Department of Gastroenterology, Postgraduate \\ Institute of Medical Education and Research, Chandigarh, 160012, \\ India (e-mail: hmandavdhare760@gmail.com)
}

J Digest Endosc 2019;10:142-149

\begin{abstract}
Keywords

- third space

- per oral endoscopic myotomyfundoplication

- robotic

- endoscopy

The last decade has seen the growth of a completely new and exciting entity called the third space endoscopy (TSE) that has brought about a paradigm shift in the way we manage various disorders of the gastrointestinal tract. The journey started with per oral endoscopic myotomy (POEM) for achalasia cardia and within a decade the concept has been exploited to its best potential for disorders including submucosal tumor resection, pyloromyotomy for gastroparesis, complete division of septum without the risk of perforation in diverticular diseases of esophagus, restoration of esophageal lumen in long strictures, restoration of bowel movement in Hirschsprung's disease, and then taking the concept to the next level of pure NOTES (natural orifice transluminal endoscopic surgery) by entering the peritoneal cavity and performing fundoplication. This review will discuss the history of TSE with brief discussion about the various applications and what has been achieved till present.
\end{abstract}

\section{Basic Concept and History of Third Space Endoscopy}

The basic concept of third space endoscopy (TSE) is the mucosal safety flap, wherein we create a mucosal bleb by injecting a solution of indigo carmine/methylene blue + saline, a few centimeters proximal to the area of interest, do a mucosotomy by giving an incision over the bleb, enter the submucosal space, and create a tunnel by dissecting the submucosal tissue and reach the area of interest ( - Fig. $\mathbf{1}$ ). The intact mucosa between the area of interest and the mucosotomy acts as a barrier protecting the mediastinum and the peritoneum from contamination from the lumen. This is the common concept in all the applications of TSE.

The seeds of this concept were sown by the pioneering work of Sumiyama et $\mathrm{al}^{1}$ when they introduced the submucosal endoscopy with mucosal flap safety. It was the landmark work of Pasricha et al in 2007 who published their animal experiment of submucosal endoscopy and myotomy of esophagus as a treatment option for achalasia cardia that paved the way for clinical studies. ${ }^{2}$ This was quickly adopted by the Japanese and, in 2008, Inoue et al published the first human case of submucosal endoscopic myotomy of esophagus $^{3}$ and subsequently published their successful case series in $2010^{4}$ and called it per oral endoscopic myotomy or POEM. As the years passed, the list of conditions that can be tackled with the help of TSE increased. In 2012, Xu et al introduced the concept of submucosal tunneling and endoscopic resection (STER) of submucosal tumors. ${ }^{5} 2013$ saw another addition, by Khashab et al of gastric POEM (G-POEM) or per oral pyloromyotomy (POP) for refractory gastroparesis. ${ }^{6}$ Subsequently in 2016, Bapaye et al introduced per rectal endoscopic myotomy (PREM) for Hirschsrung's disease. ${ }^{7}$

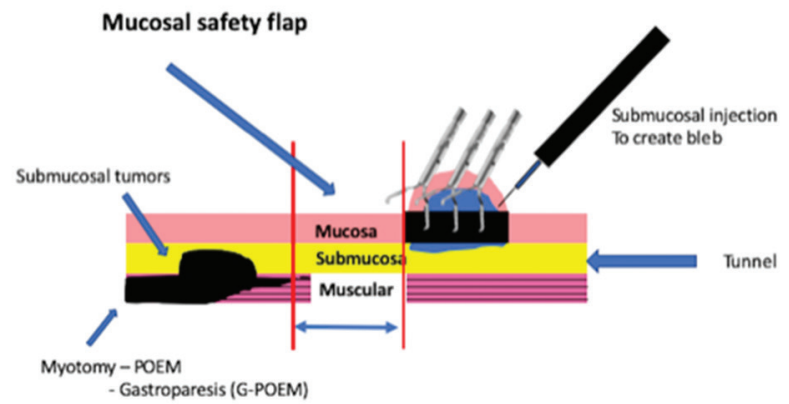

Fig. 1 The basic concept of third space endoscopy with the mucosal safety flap. G POEM, gastric per oral endoscopic myotomy. 
Wagh and Draganov introduced per oral endoscopic tunneling for restoration of esophagus (POETRE) for complete esophageal strictures ${ }^{8}$ and $\mathrm{Li}$ et al performed submucosal endoscopic septal division for Zenker's diverticulum. ${ }^{9}$ However, the real game changer and true potential of TSE was explored by Inoue et al in 2019 when they performed pure NOTES (natural orifice transluminal endoscopic surgery) by entering the peritoneal cavity through the myotomy site of achalasia and performing fundoplication. ${ }^{10}$

\section{Per Oral Endoscopic Myotomy (POEM) for Achalasia Cardia}

Achalasia cardia, as known, is a myenteric plexopathy of probable autoimmune origin that leads to aperistalsis of esophageal body with failure of relaxation of the lower esophageal sphincter (LES) leading to dysphagia and weight loss (-Fig. 2). Traditionally, the treatment has been pneumatic dilation (PD) and laparoscopic Heller's myotomy (LHM) for those nonresponsive to PD. However, past 2010, with the introduction of POEM, there has been a paradigm shift in the management of this disorder. After a decade of its introduction, now we have enough data to suggest POEM as the modality of choice as it is incisionless, it tackles the whole LES and also the esophageal body in patients with type-III achalasia, requires short-hospital stay and has durable long-term efficacy of $>85 \%{ }^{11,12} \mathrm{~A}$ recent randomized trial in treatment naïve patients has shown the efficacy of POEM to be $>90 \%$ at 2 years when compared with 54\% for PD. ${ }^{13}$ Moreover, patients with failed LHM and PD and those with end-stage burnt out disease (sigmoid esophagus) also show a good technical and clinical success with POEM $^{14-16}$ (-Table 1). Taken together, POEM appears to be the panacea for complete spectrum of presentations of achalasia from naïve to treatment failures and also burnt out disease.

\section{Equipment for performing TSE and steps of POEM procedure for achalsia cardia}

The equipments required for performing TSE are more or less same, whether we perform POEM/STER/G-POEM/PREM/ POETRE, with minor modifications. - Table 2 lists the equipments for TSE. For POEM for achalasia cardia, the patient is kept nil per oral 24 hours before the procedure and endoscopy is performed to clear the esophagus of any food residue. One hour prior to the procedure the patient receives a single shot of an intravenous antibiotic and proton pump inhibitor. The procedure is done under general anesthesia.
A high-definition gastroscope with a transparent distal attachment is used for the procedure. For insufflations, $\mathrm{CO}_{2}$ is used with the help of insufflation unit (UCR, Olympus, Tokyo, Japan) attached to the gastroscope through a low flow/extra low flow tubing (MAJ-1742/MAJ-1816, Olympus, Tokyo, Japan). Around 10-cm proximal to the gastroesophageal junction, a mucosal bleb is raised with the help of 23 $G$ endoscopic sclerotherapy needle and a solution of normal saline and indigo carmine, by injecting around 15 to $20 \mathrm{~mL}$ of the solution. After this, with the help of triangular tip J electrosurgical knife (Olympus, Tokyo, Japan) and electrosurgical cautery (ENDO cut $\mathrm{Q}$ effect 3, cut duration 1 and interval 6 and spray coagulation mode effect 2, Max Watt-50), a mucosal incision of around 2 to $4 \mathrm{~cm}$ is given over the bleb and then edges undermined to help endoscope entry into the submucosal space. Once the submucosal space is entered, a tunnel is created with the help of spray coagulation till we reach 2 to $3 \mathrm{~cm}$ beyond the LES as confirmed by (1) appearance of spindle shaped vessels, (2) Y-shaped perforators, (3) tunnel becoming roomier, and (4) on taking the scope in to the stomach and on retroflexion, the bluish bleb of the tunnel can be seen extending along the lesser curvature. During tunneling, blood vessels that are encountered are tackled with either spray coagulation or if a larger vessel is encountered, then it is coagulated with the help of Coagrasper hemostatic forceps (soft coagulation mode, Effect 4, Max Watt-80, Olympus, Tokyo, Japan). After the tunneling is complete, myotomy is begun around $3-\mathrm{cm}$ distal to the mucosal incision and extended till the tunnel ending. Once the myotomy is complete and thorough hemostasis is confirmed, the mucosal incision is closed with the help of long-hemostatic clips. If during the procedure any mucosal injury occurs, it is tackled with the help of hemoclips. Postprocedure, the patient is monitored in the intensive care unit (ICU) and kept nil per oral for 24 hours. If everything is fine, the patient is advised to take clear liquids after 24 hours and then semisolid diet and discharged after 48 hours of observation.

\section{Per Oral Endoscopic Myotomy for Spastic Disorders of Esophagus}

The biggest advantage of POEM over LHM is the liberty to calibrate the length of myotomy as per the need. In spastic disorders (type-III achalasia, distal esophageal spasm and jackhammer esophagus), we need to perform a long myotomy to cover the entire smooth muscle part of esophagus, thus POEM naturally becomes the treatment of choice.

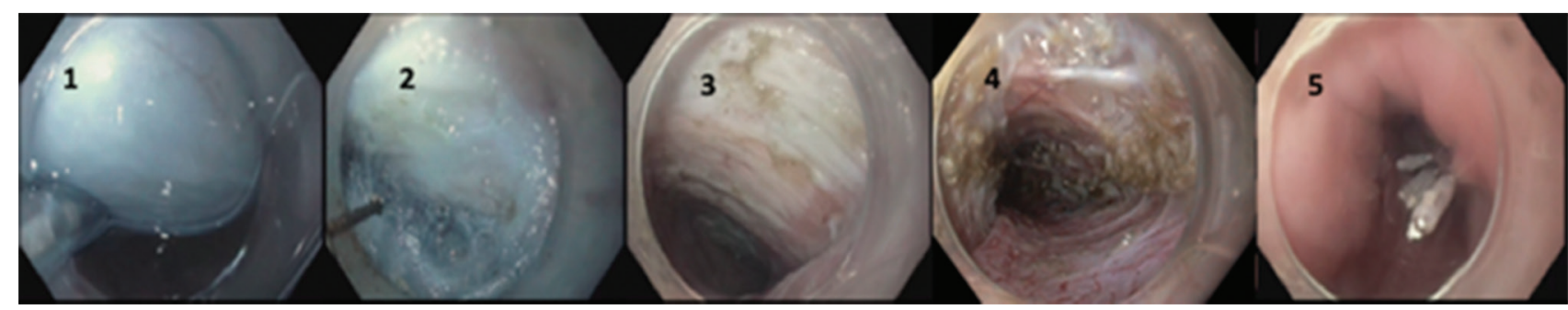

Fig. 2 Steps of POEM for achalasia cardia: (1) mucosal bleb for incision and entry into the submucosal space, (2) tunneling, (3) completed tunnel, (4) full thickness myotomy, and (5) closure of incision with the help of clips. POEM, per oral endoscopic myotomy. 
Table 1 Studies on results of POEM in failed LHM and PD

\begin{tabular}{|c|c|c|c|c|c|}
\hline $\begin{array}{l}\text { Studies of POEM in failed } \\
\text { LHM }\end{array}$ & Type of study & $\begin{array}{l}\text { Prior failed } \\
\text { LHM }\end{array}$ & $\begin{array}{l}\text { Follow-up duration } \\
\text { (mo) }\end{array}$ & $\begin{array}{l}\text { Technical } \\
\text { success (\%) }\end{array}$ & $\begin{array}{l}\text { Clinical } \\
\text { success (\%) }\end{array}$ \\
\hline Tyberg et al $2018^{14}$ & $\begin{array}{l}\text { Multicentre prospective } \\
\text { cohort }\end{array}$ & 51 & 24.4 (average) & 100 & 94 \\
\hline Zhang et al $2018^{36}$ & Retrospective & 46 & 28 (median) & 100 & 95.7 \\
\hline $\begin{array}{l}\text { Ngamruengphong } \\
\text { et al } 2017^{37}\end{array}$ & $\begin{array}{l}\text { Multicentre retrospec- } \\
\text { tive cohort }\end{array}$ & $\begin{array}{l}90 \\
90 \text { (naïve) }\end{array}$ & $\begin{array}{l}8.5 \\
9 \text { (median) }\end{array}$ & $\begin{array}{l}98 \\
100\end{array}$ & $\begin{array}{l}80 \\
94\end{array}$ \\
\hline Kristensen et al $2017^{38}$ & Retrospective & 14 & $\begin{array}{l}3 \\
12 \\
24\end{array}$ & 100 & $\begin{array}{l}\text { Reduced over } \\
\text { time }\end{array}$ \\
\hline Zhou et al $2013^{39}$ & $\begin{array}{l}\text { Single-center prospec- } \\
\text { tive cohort }\end{array}$ & 12 & $10.4 \pm 3.1$ (mean) & 100 & 91.7 \\
\hline \multicolumn{6}{|l|}{ Studies of POEM in failed PD } \\
\hline Tang et al $2015^{40}$ & $\begin{array}{l}\text { Retrospective case } \\
\text { control }\end{array}$ & $\begin{array}{l}22 \text { prior PD } \\
39 \text {-controls }\end{array}$ & $1 \mathrm{y}$ & 100 & $\begin{array}{l}95.5 \\
92.3\end{array}$ \\
\hline Ling et al $2014^{41}$ & $\begin{array}{l}\text { Prospective case } \\
\text { control }\end{array}$ & $\begin{array}{l}21 \text { failed PD } \\
30 \text {-controls }\end{array}$ & $1.1 \pm 0.3 y$ & 100 & 88 \\
\hline
\end{tabular}

Abbreviations: LHM, laparoscopic Heller's myotomy; PD, pneumatic dilation; POEM, per oral endoscopic myotomy.

Table 2 List of instruments for third space endoscopy

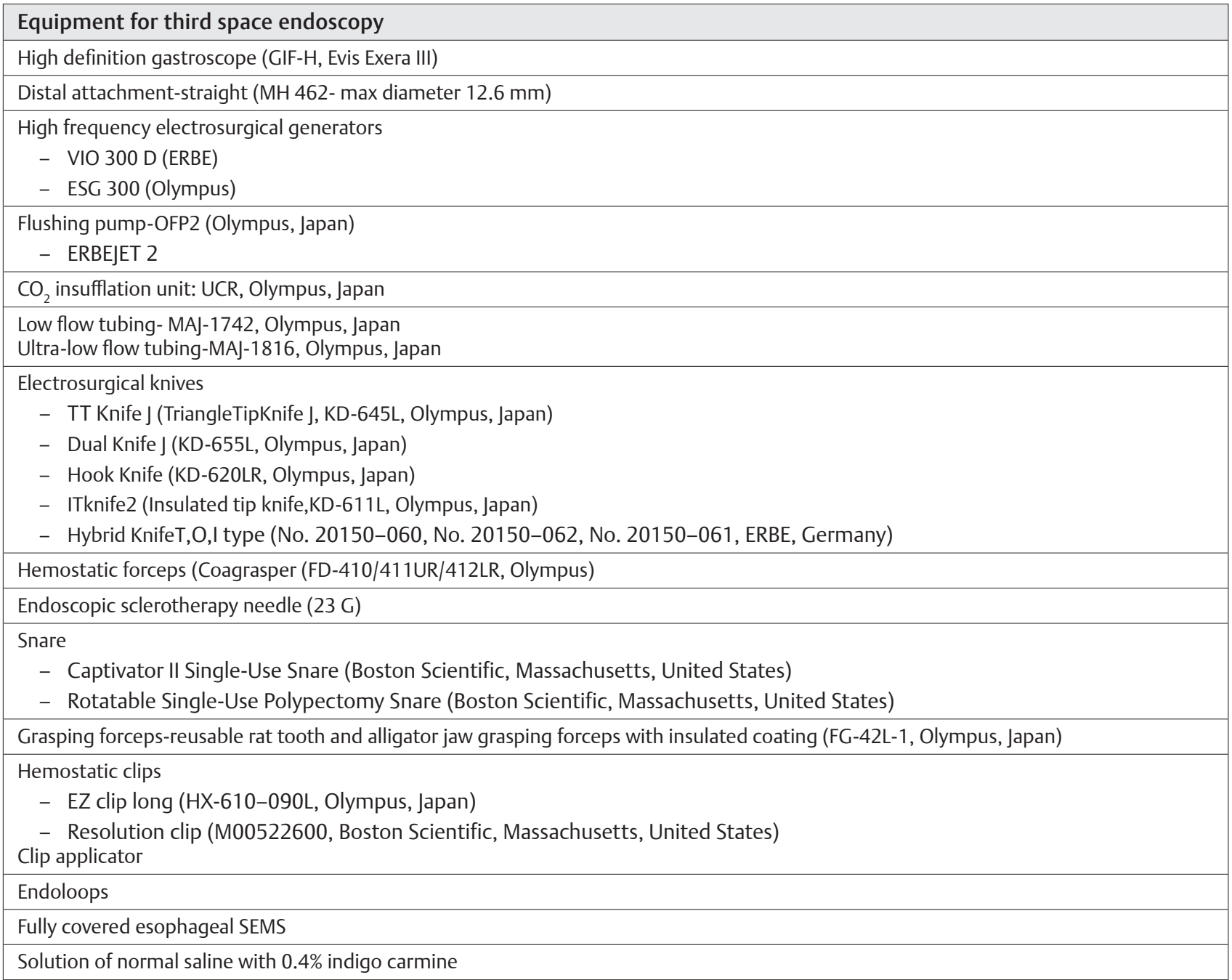

Abbreviation: SEMS, self-expanding metal stent. 
A recent systematic review and meta-analysis has shown a pooled clinical efficacy of POEM in spastic disorders of esophagus of $>90 \%{ }^{17}$

\section{Adverse Events in Per Oral Endoscopic Myotomy (Common to other Third Space Endoscopic Procedures)}

With a long experience, it has now been established that POEM or any TSE is quite safe to perform in expert hands and as the experience has evolved, adverse events have become infrequent to be less than $4 \% .18,19$ The basic prerequisite for TSE procedures is creation of a submucosal tunnel for which $\mathrm{CO}_{2}$ insufflation is needed and, hence, insufflation related events are the most frequently encountered intraprocedural events. These may be in the form of subcutaneous emphysema, capnothorax, capnopercardium, and capnoperitoneum. Most of these are inconsequential as the $\mathrm{CO}_{2}$ diffuses out fast and hence are considered as adverse events only when they require intervention in the form of intercostal drain placement for capnothorax or needle aspiration with a 16- to 18-gauge needle under water seal for capnoperitoneum. They occur overall in $<2 \%$ of patients. ${ }^{20}$ Most of the time whenever such events are encountered, a check is kept on the end tidal $\mathrm{CO}_{2}$ and peak pressures and if the anesthetist feels that there is a problem with ventilating the patient, the procedure is given a pause for 5 to 10 minutes and once the values for above parameters settle, it is restarted.

Another common scenario encountered is mucosal injury leading to breach of the protective mucosal flap exposing the mediastinum to the luminal contents. While most studies report it to be $<5 \%,{ }^{20,21}$ a large cohort of 1,680 patients reported it to be $17 \%{ }^{22}$ Most of these occur during the learning curve, with gastroesophageal junction being the commonest site, given the narrow space for working. Other factors that contribute to mucosotomies are submucosal fibrosis, anterior approach, bursts of spray coagulation current given during tunneling toward the mucosal site, or use of coagulation forceps for hemostasis toward the mucosal site.

The mucosal injuries can be type-I injuries (90\%) which are small scalds, mucosal blebs, or linear whitish cuts exposing the submucosa short of perforation, and are easy to repair or type II (10\%) which are large, full thickness perforations exposing the tunnel to the lumen. Most can be easily repaired with the help of endoclips, while a few large defects with ragged irregular edges might require additional modalities in the form of clips with endoloop, fibrin glue, over the scope clips (OTSC), or fully covered self-expanding metal stents. ${ }^{23}$

Another common intraprocedural problem encountered is bleeding. It can occur during the incision over the mucosal bleb, especially if the cut taken is superficial, which exposes the rich capillary network over the mucosa. It is sometimes difficult and time consuming to control. It can also occur while tunneling and, especially, on the gastric side where we encounter large $\mathbf{Y}$-shaped perforators and, finally while doing myotomy. Most of the bleeding episodes can be tackled immediately by either using spray coagulation or if the vessel is large, then by using Coagrasper. Bleeding requiring conversion to surgery or blood transfusion is a rare event $(<1 \%)$, so is delayed bleeding requiring reexploration. ${ }^{21}$

Other rare problems encountered are delayed mucosal barrier failure, mediastinitis, empyema, pneumonia, and cardiac arrhythmias. ${ }^{21}$

\section{Long-Term Adverse Events Specific to Per Oral Endoscopic Myotomy for Achalasia}

One of the major drawbacks of POEM, as opposed to LHM, is lack of reflux barrier as is created in the form of fundoplication in LHM. As a result, gastroesophageal reflux (GERD) has been one of the major concerns related to it. The 24 -hour pH studies show evidence of reflux in up to $40 \%$ of patients and symptoms of GERD are seen in half of them. ${ }^{24}$ Although initially it was thought that anterior approach of POEM would cause less GERD as compared to the posterior approach, a recent trial has shown similar rates of GERD with both approaches; the authors advocated preservation of sling fibers by going toward right of the perforators encountered on the gastric side..$^{25}$ Finally, the long-term effect of GERD in the form peptic stricture and Barrett's esophagus remains a concern as a few case reports have shown. ${ }^{26-28}$

\section{Submucosal Tunneling Endoscopic Resection (STER)/Per Oral Endoscopic Tumor Resection}

This application of TSE has ushered in a new era of incisionless surgery for submucosal tumors of GI tract. It has completely circumvented the problem of single-lung ventilation that is needed in thoracoscopic excision of these tumors in the esophagus. Here, we create a mucosotomy, a few centimeters proximal to the lesion, enter the submucosal space, create a tunnel, and reach the tumor and dissect it from surrounding structures and then remove it. The mucosal safety flap prevents contamination of mediastinum and peritoneum even when we create a defect in lamina propria and serosa. The only disadvantage is that tumors with transverse diameter $>3 \mathrm{~cm}$ have more chance of piecemeal resection. ${ }^{29}$ A systematic review and meta-analysis involving $>1,000$ patients and lesions has shown complete and en bloc resection rate of $>95 \% .{ }^{30}$ Most common tumors were leiomyomas followed by gastro-intestinal stromal tumors (GISTs) and others. The pooled prevalence of subcutaneous emphysema, capnothorax, capnoperitoneum, and perforation was 14.8, $6.1,6.8$, and $5.6 \%$, respectively. ${ }^{30}$ Subcutaneous emophysema and capnothorax were found to be more common in patients with esophageal lesions where as capnoperitoneum and perforation in patients with lesions in the stomach. Bleeding was noted in 1.7 to $17 \%$, although the latter figure appears to be an overestimate. There were no STER related deaths

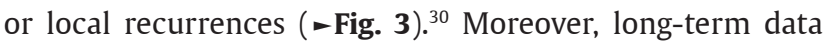
of $>5$ years of follow-up has shown no local recurrence or distant metastasis. ${ }^{29}$ On comparison of STER with other procedures available for submucosal tumors, it has a shorter procedure time and hospital stay and is especially useful for tumors less than $3.5 \mathrm{~cm}$ in diameter ( $\mathbf{- T a b l e} \mathbf{3}$ ). 


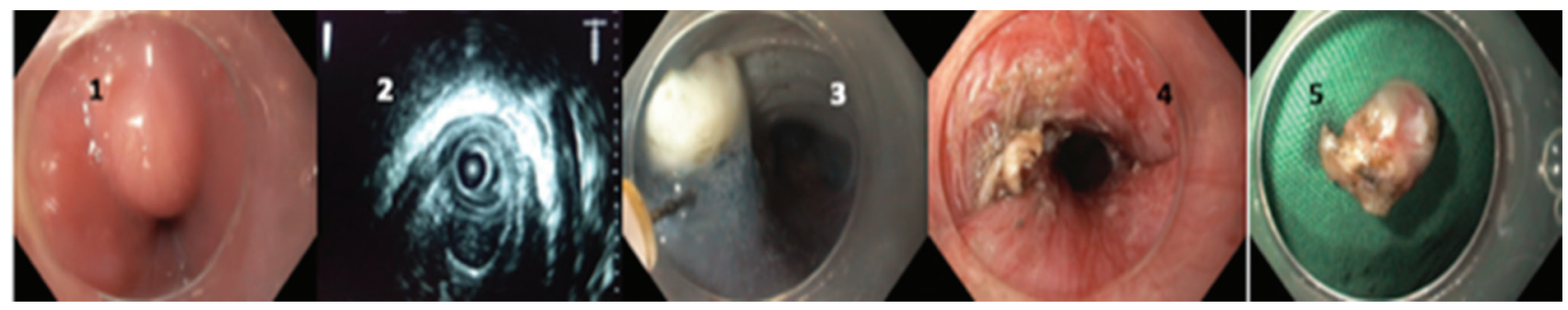

Fig. 3 Steps of STER: (1) a submucosal lesion just above the GE junction, (2) Endoscopic ultrasound miniprobe showing lesion arising from muscularis propria, (3) completed tunnel and lesion dissected from surrounding structures, (4) lesion bed in the muscularis propria post resection, and (5) en bloc resected specimen. GE, gastroesophageal; STER, submucosal tunneling and endoscopic resection.

Table 3 Comparison of STER with EFTR, ESE, and VATE

\begin{tabular}{|c|c|c|}
\hline Procedure & $\begin{array}{l}\text { Advantage (as com- } \\
\text { pared with STER) }\end{array}$ & $\begin{array}{l}\text { Disadvantage (as } \\
\text { compared with } \\
\text { STER) }\end{array}$ \\
\hline $\mathrm{EFTR}^{42,43}$ & $\begin{array}{l}\text { - Can be used at any } \\
\text { location } \\
\text { - Larger size of } \\
\text { tumors }\end{array}$ & $\begin{array}{l}\text { - longer suture time } \\
\text { - larger number of } \\
\text { clips for closure } \\
\text { - } \text { prolonged post- } \\
\text { operative hospital } \\
\text { stay }\end{array}$ \\
\hline $\mathrm{ESE}^{44}$ & $\begin{array}{l}\text { - Less time } \\
\text { consuming } \\
\text { - Low skill and equip- } \\
\text { ment requirement }\end{array}$ & $\begin{array}{l}\text { - Higher chance of } \\
\text { perforation } \\
\text { - Not suitable for } \\
\text { lesions from deep } \\
\text { MP }\end{array}$ \\
\hline VATE $^{45,46}$ & $\begin{array}{l}\text { - } \text { More effective for } \\
\text { large }(>3.5 \mathrm{~cm}) \\
\text { tumor size, irregular } \\
\text { margin } \\
\text { - Lesser gas related } \\
\text { complications }\end{array}$ & $\begin{array}{l}\text { - } \text { Higher cost } \\
\text { - } \text { Longer procedure } \\
\text { time } \\
\text { - } \quad \text { Longer postopera- } \\
\text { tive hospital stay }\end{array}$ \\
\hline
\end{tabular}

Abbreviations: EFTR, endoscopic full thickness resection; ESE, endoscopic submucosal evacuation; STER, submucosal tunneling and endoscopic resection; VATE, video assisted thoracoscopic enucleation.

\section{Gastric Per Oral Endoscopic Myotomy (G-POEM) for Refractory Gastroparesis}

Gastroparesis is a chronic debilitating disorder of delayed gastric emptying in the absence of mechanical obstruction (-Fig. 4). ${ }^{31}$ The etiological spectrum includes diabetes mellitus, postsurgical, idiopathic, and miscellenous. ${ }^{31}$ Medical therapy is effective in 50 to $60 \%$ of patients with therapies like gastric electrical stimulation, Botox injection and selfexpanding metal stent (SEMS) being of questionable efficacy. Laparoscopic pyloroplasty has good efficacy and safety and acts as a salvage option when first-line therapies fail. However, with the advent of TSE, this disorder can now be tackled with incisionless surgery with the help of G-POEM. Here, applying the same four principle steps of POEM, we do a mucosotomy 4 to $5 \mathrm{~cm}$ proximal to the pyloric rim, create and extend a tunnel $1 \mathrm{~cm}$ beyond the ring, do either a selective circular/full thickness myotomy, and close the incision with clips. A recent systematic review and meta-analysis comparing G-POEM with surgical pyloloroplasty has shown equal efficacy (based on gastroparesis cardinal symptom index [GCSI] 75.8 vs. $77.3 \%$ and based on 4-hour gastric emptying scintigraphy [GES] 85.1 vs. 84\%) and safety (adverse events 11.4 vs. $11 \%) .^{32}$ The adverse events in the G-POEM group in decreasing order of frequency were bleeding $(0.04 \%)$, abdominal pain $(0.03 \%)$, capnoperitoneum $(0.02 \%)$, perforation $(0.01 \%)$, ulcer $(0.01 \%)$, pyloric stricture (two cases), dehydration (two cases), and abscess (one case). The advantages of G-POEM were less operative time and incisionless surgery. ${ }^{32}$ As more, robust data emerges G-POEM might become the treatment of choice in refractory gastroparesis and in a certain subset of patients, it might be the upfront treatment.

\section{Z/D POEM for Diverticular Diseases of Esophagus (Z-POEM: Zenker's-POEM) D-POEM; Diverticular-POEM)}

The mucosal safety flap in diverticular diseases of esophagus has proven to be a boon by allowing to complete dissection of the septum with no risk of perforation ( - Fig. 5). With

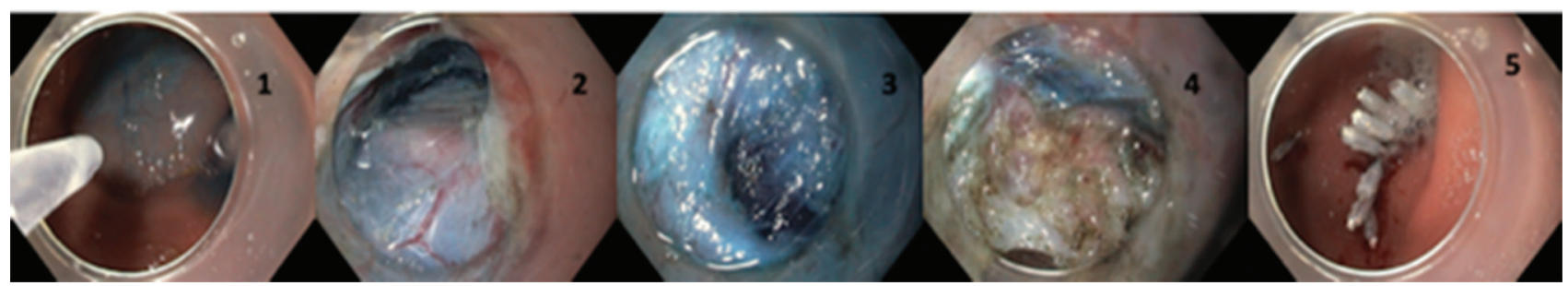

Fig. 4 Steps of G-POEM: (1) raised mucosal bleb by submucosal injection 5-cm proximal to the pyloric ring, (2) tunnel, (3) pyloric ring seen from the tunnel as arc of muscle at the 7 o' clock position with curtain of duodenal mucosa at the 2 o' clock position, (4) full thickness myotomy of the pyloric muscle, and 5) closure of incision with the help of clips. G POEM, gastric per oral endoscopic myotomy. 
the same four-step principle, we do a mucosotomy $2-\mathrm{cm}$ proximal to the septum and create tunnel on both sides of the septum on the diverticular side till its base and on the esophageal side 2 to $3 \mathrm{~cm}$ beyond the base of septum. And then completely dissect the septum till its base and close the mucosotomy with clips. A recent case series with 1 year of follow-up of 25 patients (20 Zenker's and 5 epiphrenic diverticula) has shown $100 \%$ technical and $86 \%$ clinical success. ${ }^{33}$

\section{Per Rectal Endoscopic Myotomy (PREM) for Hirchsprung's Disease}

The four-step principle of POEM has also been explored in Hirchsprung's disease which is characterized by aganglionosis in the anorectal region leading to failure of relaxation of the anal sphincter during defecation. Here, we do mucosotomy just above the anal verge, create a tunnel 1 to $2 \mathrm{~cm}$ beyond the transition zone and do myotomy till the end of tunnel and close the incision with clips. Although exciting, only 2 case reports are available. ${ }^{7,34}$ The lack of enthusiasm may be due to the risk of injuring the external anal sphincter leading to incontinence.

\section{Per Oral Endoscopic Tunneling for Restoration of Esophagus (POETRE) for Complete Esophageal Obstruction}

This is one the challenging applications of TSE where long esophageal strictures $>3 \mathrm{~cm}$ are tackled by restoring the lumen through the tunnel. Here, an antegrade tunnel is created till the stricture site and then through a gastrostomy site, an ultrathin scope is introduced in retrograde fashion and a retrograde tunnel is created till the stricture site and then antegrade tunnel site is dissected and incised till we see the esophageal lumen. This is followed by passage of a guidewire and deployment of fully covered metal SEMS restoring the esophageal lumen. Similar to PREM, this is an exciting application of TSE. However, after the original case series of four patients it has not been replicated yet. ${ }^{8}$

\section{Per Oral Endoscopic Myotomy + Fundoplication (POEM + F)}

The latest addition to the application of TSE and a game changer is POEM + fundoplication (F) which has ushered in the era of pure NOTES ( $\boldsymbol{- F i g}$. 6). Here, after completing

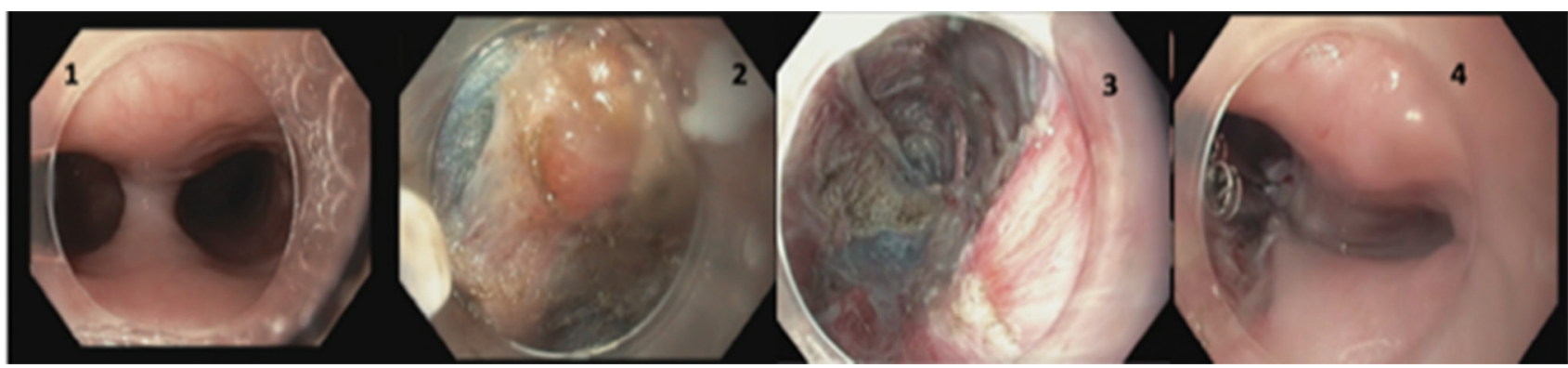

Fig. 5 Steps of L-POEM: (1) endoscopic view of the Zenker's diverticulum, (2) tunneling on the diverticular side till its base and on the esophageal side 2 to $3 \mathrm{~cm}$ beyond the base, (3) complete dissection of the septum, and (4) closure of the incision with the help of clips.

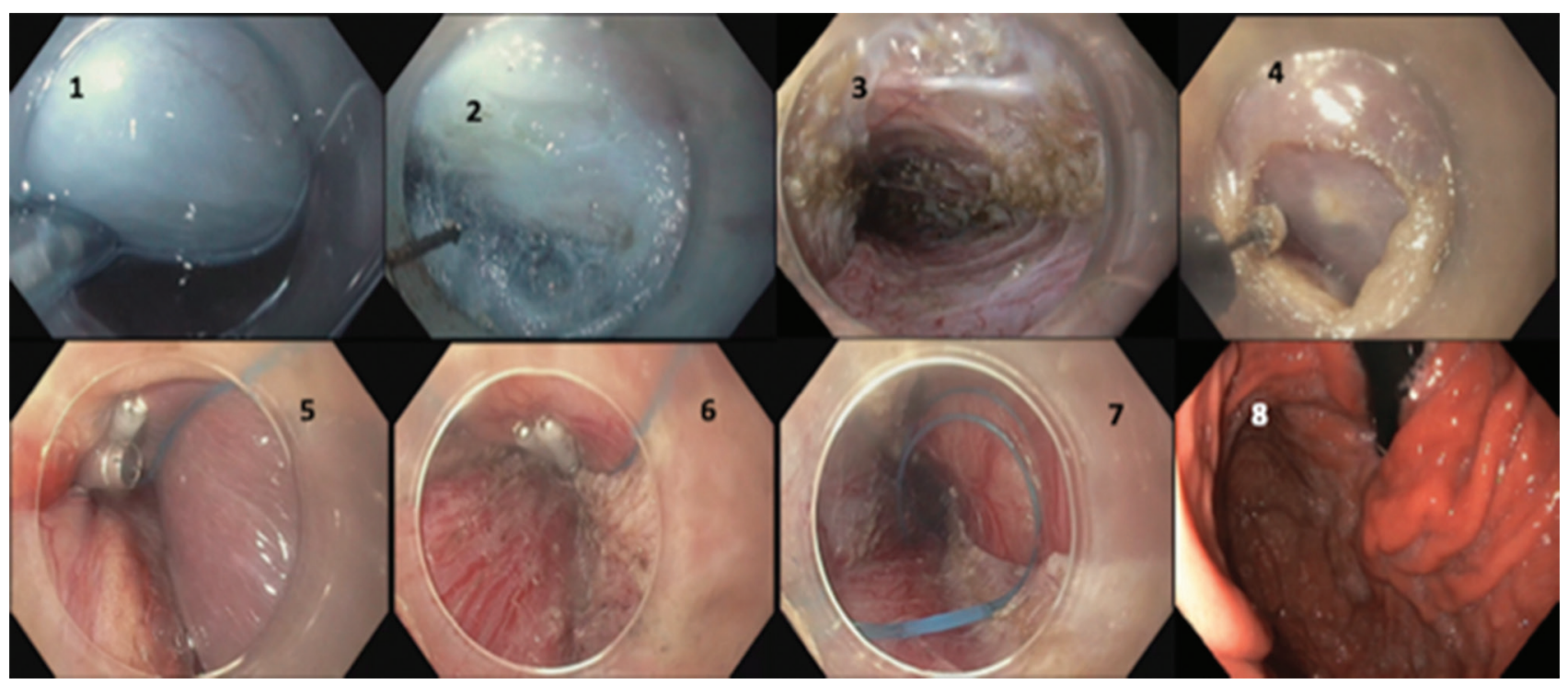

Fig. 6 Steps of POEM + F: (1) mucosal bleb for incision and entry through the anterior approach, (2) tunneling, (3) full thickness anterior myotomy, (4) creating a window in the peritoneal membrane for entry into the peritoneal cavity, (5) one end of the endoloop attached by clips on the stomach, (6) other end of the endoloop attached to the distal edge of the myotomy on the right side, (7) tightened loop, and (8) endoscopic view of wrap after tightening of the loop. POEM + F, per oral endoscopic myotomy + fundoplication. 
anterior myotomy, we create a defect in the peritoneal membrane and enter the peritoneal cavity and locate the fundus of stomach. Then with the help of clips and an endoloop, attach one end of the loop to the stomach and the other end to the right edge of the distal end of the myotomy; then tighten the loop. In doing so, a wrap is created (where the fundus comes over and attaches to the myotomy site), thus creating a sort of antireflux barrier. ${ }^{10}$

\section{What Is There in the Future?}

With the entry into the peritoneal cavity through POEM + F, it is clear that in future we will see endoscopic procedures being done inside the peritoneal cavity. However, currently to keep up with it, we need instruments that have inbuilt capability of cutting, dissecting, cauterizing, and suturing the tissue. To facilitate those various prototypes, robotic devices are in the offing. The FLEX robotic system from Medrobotics provides a stable platform to perform endoscopic surgeries with the flexibility of an endoscope and strength of laparoscopic instruments. ${ }^{35}$ It can be used to perform full thickness resections with ease with the two working channels allowing bimanual manipulation of the lesion with the instruments. Although it was originally developed for head, neck, and hypopharyngeal surgeries, its use can be extended to upper GI and colonic surgeries if longer operating arms are made available. Also, various experimental robot assisted technologies are under development with robot-driven locomotion (e.g., robotic steering and automated lumen centralization (RS-ALC, Netherlands) and instrument manipulation (e.g., MASTER, EndoMASTER Pte., Singapore) being some of them. ${ }^{35}$

\section{Conclusion}

TSE has opened up a completely new world of therapeutic endoscopy and caused a paradigm shift in the management of various disorders of GI tract. In the coming years, its usage will be driven by the imagination of the endoscopists and development of new instruments.

\section{Funding \\ None.}

\section{Conflict of Interest}

None declared.

\section{References}

1 Sumiyama K, Tajiri H, Gostout CJ. Submucosal endoscopy with mucosal flap safety valve (SEMF) technique: a safe access method into the peritoneal cavity and mediastinum. Minim Invasive Ther Allied Technol 2008;17(6):365-369

2 Pasricha PJ, Hawari R, Ahmed I, et al. Submucosal endoscopic esophageal myotomy: a novel experimental approach for the treatment of achalasia. Endoscopy 2007;39(9):761-764

3 Inoue $\mathrm{H}$, Minami H, Satodate H, Kudos E. First clinical experience of submucosal endoscopic esophageal myotomy for esophageal achalasia with no skin incision. Gastrointest Endosc 2009;69(5):AB122
4 Inoue $\mathrm{H}$, Minami H, Kobayashi $\mathrm{Y}$, et al. Peroral endoscopic myotomy (POEM) for esophageal achalasia. Endoscopy 2010;42(4):265-271

$5 \mathrm{Xu}$ M-D, Cai M-Y, Zhou P-H, et al. Submucosal tunneling endoscopic resection: a new technique for treating upper GI submucosal tumors originating from the muscularis propria layer (with videos). Gastrointest Endosc 2012;75(1):195-199

6 Khashab MA, Stein E, Clarke JO, et al. Gastric peroral endoscopic myotomy for refractory gastroparesis: first human endoscopic pyloromyotomy (with video). Gastrointest Endosc 2013;78(5):764-768

7 Bapaye A, Wagholikar G, Jog S, et al. Per rectal endoscopic myotomy for the treatment of adult Hirschsprung's disease: First human case (with video). Dig Endosc 2016;28(6):680-684

8 Wagh MS, Draganov PV. Per-oral endoscopic tunneling for restoration of the esophagus: a novel endoscopic submucosal dissection technique for therapy of complete esophageal obstruction. Gastrointest Endosc 2017;85(4):722-727

9 Li Q-L, Chen W-F, Zhang X-C, et al. Submucosal tunneling endoscopic septum division: a novel technique for treating Zenker's diverticulum. Gastroenterology 2016;151(6):1071-1074

10 Inoue $\mathrm{H}$, Ueno A, Shimamura Y, et al. Peroral endoscopic myotomy and fundoplication: a novel NOTES procedure. Endoscopy 2019;51(2):161-164

11 Schlottmann F, Luckett DJ, Fine J, Shaheen NJ, Patti MG. Laparoscopic Heller myotomy versus peroral endoscopic myotomy (POEM) for achalasia: a systematic review and meta-analysis. Ann Surg 2018;267(3):451-460

12 Li Q-L, Wu Q-N, Zhang X-C, et al. Outcomes of per-oral endoscopic myotomy for treatment of esophageal achalasia with a median follow-up of 49 months. Gastrointest Endosc 2018;87(6):1405-14e3

13 Ponds FA, Fockens P, Lei A, et al. Effect of peroral endoscopic myotomy vs pneumatic dilation on symptom severity and treatment outcomes among treatment-naive patients with achalasia: a randomized clinical trial. JAMA 2019;322(2):134-144

14 Tyberg A, Sharaiha RZ, Familiari P, et al. Peroral endoscopic myotomy as salvation technique post-Heller: international experience. Dig Endosc 2018;30(1):52-56

15 Nabi Z, Ramchandani M, Chavan R, et al. Peroral endoscopic myotomy in treatment-naïve achalasia patients versus prior treatment failure cases. Endoscopy 2018;50(4):358-370

16 Hu J-W, Li Q-L, Zhou P-H, et al. Peroral endoscopic myotomy for advanced achalasia with sigmoid-shaped esophagus: longterm outcomes from a prospective, single-center study. Surg Endosc 2015;29(9):2841-2850

17 Chandan S, Mohan BP, Chandan OC, et al. Clinical efficacy of per-oral endoscopic myotomy (POEM) for spastic esophageal disorders: a systematic review and meta-analysis. Surg Endosc 2019

18 Stavropoulos SN, Modayil RJ, Friedel D, Savides T. The international per oral endoscopic myotomy survey (IPOEMS): a snapshot of the global POEM experience. Surg Endosc 2013;27(9):3322-3338

19 Inoue $\mathrm{H}$, Sato $\mathrm{H}$, Ikeda $\mathrm{H}$, et al. Per-oral endoscopic myotomy: a series of 500 patients. J Am Coll Surg 2015;221(2):256-264

20 Haito-Chavez Y, Inoue $\mathrm{H}$, Beard KW, et al. Comprehensive analysis of adverse events associated with per oral endoscopic myotomy in 1826 patients: an international multicenter study. Am J Gastroenterol 2017;112(8):1267-1276

21 Nabi Z, Reddy DN, Ramchandani M. Adverse events during and after per-oral endoscopic myotomy: prevention, diagnosis, and management. Gastrointest Endosc 2018;87(1):4-17

22 Zhang X-C, Li Q-L, Xu M-D, et al. Major perioperative adverse events of peroral endoscopic myotomy: a systematic 5-year analysis. Endoscopy 2016;48(11):967-978 
23 Wang Y, Liu Z-Q, Xu M-D, et al. Clinical and endoscopic predictors for intraprocedural mucosal injury during per-oral endoscopic myotomy. Gastrointest Endosc 2019;89(4):769-778

24 Repici A, Fuccio L, Maselli R, et al. GERD after per-oral endoscopic myotomy as compared with Heller's myotomy with fundoplication: a systematic review with meta-analysis. Gastrointest Endosc 2018;87(4):934-943.e18

25 Tan Y, Lv L, Wang X, et al. Efficacy of anterior versus posterior per-oral endoscopic myotomy for treating achalasia: a randomized, prospective study. Gastrointest Endosc 2018;88(1):46-54

26 Werner YB, Costamagna G, Swanström LL, et al. Clinical response to peroral endoscopic myotomy in patients with idiopathic achalasia at a minimum follow-up of 2 years. Gut 2016;65(6):899-906

27 Hungness ES, Sternbach JM, Teitelbaum EN, Kahrilas PJ, Pandolfino JE, Soper NJ. Per-oral endoscopic myotomy (POEM) after the learning curve: durable long-term results with a low complication rate. Ann Surg 2016;264(3):508-517

28 Ichkhanian Y, Benias P, Khashab MA. Case of early Barrett cancer following peroral endoscopic myotomy. Gut 2019;68 (12):2107-2110

29 Onimaru M, Inoue H, Bechara R, et al. Clinical outcomes of peroral endoscopic tumor resection for submucosal tumors in the esophagus and gastric cardia. Dig Endosc 2019

30 Lv X-H, Wang C-H, Xie Y. Efficacy and safety of submucosal tunneling endoscopic resection for upper gastrointestinal submucosal tumors: a systematic review and meta-analysis. Surg Endosc 2017;31(1):49-63

31 Camilleri M, Parkman HP, Shafi MA, Abell TL, Gerson L; American College of Gastroenterology. Clinical guideline: management of gastroparesis. Am J Gastroenterol 2013;108 (1):18-37,quiz38

32 Mohan BP, Chandan S, Jha LK, et al. Clinical efficacy of gastric per-oral endoscopic myotomy (G-POEM) in the treatment of refractory gastroparesis and predictors of outcomes: a systematic review and meta-analysis using surgical pyloroplasty as a comparator group. Surg Endosc 2019

33 Maydeo A, Patil GK, Dalal A. Operative technical tricks and 12-month outcomes of diverticular peroral endoscopic myotomy (D-POEM) in patients with symptomatic esophageal diverticula. Endoscopy 2019;51(12):1136-1140

34 Bapaye A, Bharadwaj T, Mahadik M, et al. Per-rectal endoscopic myotomy (PREM) for pediatric Hirschsprung's disease. Endoscopy 2018;50(6):644-645

35 Yeung BPM, Chiu PWY. Application of robotics in gastrointestinal endoscopy: A review. World J Gastroenterol 2016;22(5):1811-1825
36 Zhang X, Modayil RJ, Friedel D, et al. Per-oral endoscopic myotomy in patients with or without prior Heller's myotomy: comparing long-term outcomes in a large U.S. single-center cohort (with videos). Gastrointest Endosc 2018;87(4):972-985

37 Ngamruengphong $\mathrm{S}$, Inoue $\mathrm{H}$, Ujiki $\mathrm{MB}$, et al. Efficacy and safety of peroral endoscopic myotomy for treatment of achalasia after failed heller myotomy. Clin Gastroenterol Hepatol 2017;15(10):1531-15e3

38 Kristensen HØ, Kirkegård J, Kjær DW, Mortensen FV, Kunda $\mathrm{R}$, Bjerregaard NC. Long-term outcome of peroral endoscopic myotomy for esophageal achalasia in patients with previous Heller myotomy. Surg Endosc 2017;31(6):2596-2601

39 Zhou PH, Li QL, Yao LQ et al. Peroral endoscopic remyotomy for failed Heller myotomy: a prospective single-center study. Endoscopy 2013;45(3):161-166

40 Tang X, Gong W, Deng Z, et al. Feasibility and safety of peroral endoscopic myotomy for achalasia after failed endoscopic interventions. Dis Esophagus 2017;30(3):1-6

41 Ling T, Guo H, Zou X. Effect of peroral endoscopic myotomy in achalasia patients with failure of prior pneumatic dilation: a prospective case-control study. J Gastroenterol Hepatol 2014;29(8):1609-1613

42 Tan Y, Tang X, Guo T, et al. Comparison between submucosal tunneling endoscopic resection and endoscopic full-thickness resection for gastric stromal tumors originating from the muscularis propria layer. Surg Endosc 2017;31(8):3376-3382

43 Duan T-Y, Tan Y-Y, Wang X-H, Lv L, Liu D-L. A comparison of submucosal tunneling endoscopic resection and endoscopic full-thickness resection for gastric fundus submucosal tumors. Rev Esp Enferm Dig 2018;110(3):160-165

$44 \mathrm{Lu}$ J, Jiao T, Zheng M, Lu X. Endoscopic resection of submucosal tumors in muscularis propria: the choice between direct excavation and tunneling resection. Surg Endosc 2014;28(12):3401-3407

45 Chai N, Du C, Gao Y, et al. Comparison between submucosal tunneling endoscopic resection and video-assisted thoracoscopic enucleation for esophageal submucosal tumors originating from the muscularis propria layer: a randomized controlled trial. Surg Endosc 2018;32(7):3364-3372

46 Chen T, Lin Z-W, Zhang Y-Q et al. Submucosal tunneling endoscopic resection vs thoracoscopic enucleation for large submucosal tumors in the esophagus and the esophagogastric junction. J Am Coll Surg 2017;225(6):806-816 